\title{
Valorization and Miscellaneous Prospects of Waste Musa balbisiana Colla Pseudostem
}

\author{
Krishna Gogoi, ${ }^{1}$ Mayur Mausoom Phukan, ${ }^{1}$ Nipu Dutta, ${ }^{2}$ Salam Pradeep Singh, \\ Pitambar Sedai, ${ }^{3}$ Bolin Kumar Konwar, ${ }^{1}$ and Tarun Kumar Maji ${ }^{2}$ \\ ${ }^{1}$ Department of Molecular Biology \& Biotechnology, School of Science, Tezpur University, Assam 784028, India \\ ${ }^{2}$ Department of Chemical Sciences, School of Science, Tezpur University, Assam 784028, India \\ ${ }^{3}$ Department of Energy, School of Engineering, Tezpur University, Assam 784028, India
}

Correspondence should be addressed to Mayur Mausoom Phukan; mayur_101@yahoo.com

Received 6 May 2014; Revised 21 July 2014; Accepted 26 July 2014; Published 17 August 2014

Academic Editor: Ramaraj Boopathy

Copyright (C) 2014 Krishna Gogoi et al. This is an open access article distributed under the Creative Commons Attribution License, which permits unrestricted use, distribution, and reproduction in any medium, provided the original work is properly cited.

\begin{abstract}
Resourceful utilization of the enormous quantum of agrowastes generated via agricultural practices can be supportive in waste management, environmental upgradation, and subsequent material and energy recovery. In this regard, the present study aimed at highlighting waste banana (Musa balbisiana Colla) pseudostem (an agrowaste) as a potential bio-based feedstock with miscellaneous applications. The pseudostem was characterized by carbon, nitrogen, and hydrogen (CHN) analysis, thermogravimetric-differential thermal analysis (TGDTA), and Fourier transform infrared (FTIR) spectroscopy. Cellulose, hemicellulose, and lignin were estimated as a part of biochemical characterization. Total phenolic content, total flavonoid content, 1, 1-diphenyl-2-picrylhydrazyl (DPPH) radical scavenging assay, and ferric reducing antioxidant power (FRAP) were carried out as a part of antioxidant characterization. The waste banana pseudostem biomass (WBPB) was also tried successfully as a natural filler in polyvinyl chloride (PVC) polymer composite. Thermal properties and water uptake test of the WBPB polymer composite were accessed as a part of composite characterization. The pseudostem had calorific value (15.22 MJ/kg), high holocellulose (58.67\%), high free radical scavenging potential (69.9\%), and a low ash content (6.8\%). Additionally, the WBPB polymer composite showed improved water resistance and thermostability. The study suggests feasibility of WBPB as a prospective bioenergy feedstock, primary antioxidant source, and reinforcing agent in polymer composites.
\end{abstract}

\section{Introduction}

With green revolution hitting the block and subsequent intensification in agricultural practices, speedy increase in volumes and types of agrowastes generated is indispensable. Wide scale global distribution, renewable nature, and zero cost accessibility have already highlighted the importance of agrowastes as a potential resource for material and energy recovery. On a global scale, 140 billion metric tons of biomass are generated every year [1] of which a considerable proportion is agrowaste. Judicious utilization of this enormous quantum of agrowastes (lignocellulosic biomass) for material and energy recovery would undoubtedly aid in solving the menace of waste management and resource depletion.

Lignocellulosic biomass which represents a renewable and largely untapped source of raw feedstock for conversion into liquid and gaseous fuels, thermochemical products, and other energy-related end products [2] can assist in anthropogenic endeavors for combating energy crisis and promoting sustainable development. They might be an important contributor to the generation of petrochemical-based feedstock derived from renewable resources [3]. Energy recovery from second generation biofuel feedstock such as agrowastes in the wake of recent advances in bioenergy research might play a prominent role in decreasing mankind's reliance on conventional petro fuels in near future.

Most of the present environmental issues arise due to human activities characterized by mass production, mass consumption, and mass disposal [4]. Significant amounts of agricultural wastes are generated annually [5] and in this regard WBPB is no exception. A key insight into the search operations for energy and material recovery from agrowastes 
can be offered by WBPB. Banana pseudostem is a false stem composed of folded leaf blades and sheaths engulfing the growing point and is a potential cellulosic biomass source [6, 7]. As a postharvest measure, it is generally discarded in most parts of the world resulting in serious environmental pollution [8]. Additional disposal measures include occasional burning of these wastes, resultant emissions from which contribute a significant share to the global warming process [9]. India being the largest producer of banana in the world with an annual production of 29.8 million metric tons [10] of the fruit undoubtedly harbors the largest banana waste and contributes in no small measure to the current global warming process. Valorization of this enormous quantum of WBPB for material and energy recovery is important not only from the waste management point of view but also with regard to environmental upgradation and partially alleviating global warming.

The salient features of WBPB towards feedstock evaluation are as follows: (1) it is a prominent agrowaste, India being the leading producer [11], (2) it is renewable in nature, immensely prospective with regard to energy recovery especially for the subtropics (its predominant agroclimatic zone), (3) it is a perennial crop not restricted by seasonal availability, (4) it has high holocellulose content (58.67\%), which is indicative of prospective bioethanol production via fermentation, (5) it has high free radical scavenging potential (69.9\%), (6) it has good calorific value (15.22 MJ/kg), and (7) it has low ash content $(6.8 \%)$.

The present work is an effort to investigate WBPB as a bio-based feedstock with miscellaneous application, namely, (1) physicochemical characterization of WBPB to investigate feasibility of the biomass as a bioenergy feedstock, (2) as a primary antioxidant source to investigate the feasibility of free radical scavenging potential by WBPB and establishing their correlations with total phenolics and total flavonoids as a part of antioxidant characterization, and (3) as a reinforcing agent in polymer composite (with regard to the wide scale popularity of natural fibres owing to their low cost, easy availability, low density, high specific strength, and renewability).

\section{Materials and Methods}

2.1. Sample Preparation. The sample for this study (WBPB) was obtained from Research lab-I of the department of Molecular Biology \& Biotechnology, Tezpur University, Napaam, Assam, India. WBPB was oven dried, ground to fine particles, and finally kept in a dessicator.

2.2. FTIR Analysis. FTIR spectrum of the sample (WBPB) was recorded in a PerkinElmer Spectrum 100 spectrometer at room temperature $\left(28 \pm 2^{\circ} \mathrm{C}\right)$. Briefly, a known weight of the sample ( $1 \mathrm{mg}$ ) was mixed thoroughly with $\mathrm{KBr}(2.5 \mathrm{mg})$ in a mortar using a pestle [12]. A region in the spectral range of $4000-400 \mathrm{~cm}^{-1}$ was used for scanning.
2.3. Determination of Gross Calorific Value (GCV). GCV was calculated from the following equation [13]:

$$
\mathrm{GCV}=0.335 \mathrm{C}+1.423 \mathrm{H}-0.154 \mathrm{O}-0.154 \mathrm{~N}
$$

where $\mathrm{C}, \mathrm{H}, \mathrm{O}$, and $\mathrm{N}$ are weight percent of carbon, hydrogen, oxygen, and nitrogen on dry biomass basis.

\subsection{Determination of Net Calorific Value (NCV). NCV was} calculated from the following equation [14]:

$$
\begin{aligned}
\mathrm{NCV} & =\mathrm{GCV} \times\left(1-\frac{w}{100}\right)-2.444 \times\left(\frac{w}{100}\right) \\
& -2.444 \times\left(\frac{h}{100}\right) \times 8.936 \\
& \times\left(1-\frac{w}{100}\right) ; \quad[\mathrm{MJ} / \mathrm{Kg}, \mathrm{w} \cdot \mathrm{b}],
\end{aligned}
$$

where $2.444=$ Enthalpy difference between gaseous and liquid water at $25^{\circ} \mathrm{C} ; 8.936=M_{\mathrm{H}_{2} \mathrm{O}} / M_{\mathrm{H}_{2}}$, that is, the molecular mass relation between $\mathrm{H}_{2} \mathrm{O}$ and $\mathrm{H}_{2}$; NCV: net calorific value, GCV: gross calorific value, $h$ : concentration of hydrogen in weight $\%$, and $w$ : moisture content in weight $\%$.

2.5. CHN and Proximate Analysis. The percentage of carbon, hydrogen, and nitrogen in WBPB was determined using a PerkinElmer, 2400 Series-II analyzer. The percentage of oxygen was finally calculated by difference. The moisture content, volatile matter, and ash content of WBPB were determined according to ASTM D 3173, ASTM D 3175, and ASTM D 3174 protocols, respectively [15]. The fixed carbon content was calculated by difference.

2.6. Biochemical Analysis. Cellulose, hemicellulose, and lignin content of WBPB were determined indirectly using a Fibertec I \& M system (Foss Tecator) [16]. Finely ground sample $(2 \mathrm{~g})$ was extracted with $100 \%$ acetone $(150 \mathrm{~mL})$. Extractions were repeated several times. The residue obtained was dried and used for the determination of acid detergent fiber (ADF), neutral detergent fiber (NDF), and acid detergent lignin (ADL).

NDF was obtained after treatment with sodium lauryl sulphate and EDTA. The residue consisted of cellulose, hemicellulose, and lignin.

ADF was obtained after treatment of the residue with cetyltrimethylammonium bromide in sulphuric acid solution. The residue consisted of cellulose and lignin.

ADL was obtained after initial treatment for ADF measurement followed by removal of the cellulose fraction through extraction using $72 \% \mathrm{H}_{2} \mathrm{SO}_{4}$. The residue obtained contained only lignin.

Simple subtraction rules were used to calculate cellulose and hemicellulose: $\mathrm{ADF}-\mathrm{ADL}=$ cellulose and NDF - ADF $=$ hemicellulose. The results for lignin, cellulose, and hemicellulose were expressed as percentage dry weight (\%dw) of WBPB.

Lipid content was estimated by the Soxhlet extraction method. $12 \mathrm{~g}$ finely ground WBPB was weighed carefully and 
transferred to a cotton thimble. Petroleum ether $(120 \mathrm{~mL})$ was added to the Soxhlet extraction flask and the sample was extracted for $8 \mathrm{~h}$. The solvent was recovered by a rotary vacuum evaporator (Equitron, India) and weight of the crude lipid was recorded.

2.7. Sample Preparation for Antioxidant Analysis. $1 \mathrm{~g}$ powdered sample was extracted with $10 \mathrm{~mL}$ each of ethanol, methanol, and water at room temperature for $24 \mathrm{~h}$. The filtrates obtained were used for estimation of total phenolics, flavonoids, and antioxidant activity.

2.8. Total Phenolic Content (TPC). TPC was determined using the standard Folin-Ciocalteu method [17] with slight modifications. $100 \mu \mathrm{L}$ sample extract was reacted with $5 \mathrm{~mL}$ of $50 \%$ Folin-Ciocalteu's reagent. $4 \mathrm{~mL}$ of $20 \%$ sodium carbonate was added after $15 \mathrm{~min}$. The blank sample was prepared by replacing $100 \mu \mathrm{L}$ sample extract with $100 \mu \mathrm{L}$ deionised water. The reaction mixture was incubated in dark at ambient temperature for $30 \mathrm{~min}$. Absorbance was measured against the blank at $765 \mathrm{~nm}$ using a Thermo Scientific UV-10 (UVVis) spectrophotometer. Gallic acid was used as the reference standard. A calibration curve of gallic acid was plotted by using the absorbance values against various concentrations $(100-1000 \mu \mathrm{g} / \mathrm{mL})$ of gallic acid. All experiments were done in triplicates and the results obtained were averaged and expressed as milligram gallic acid equivalent (mg GAE)/g dry weight of the biomass.

2.9. Flavonoid Content. Flavonoid content was measured according to the aluminium chloride method [18] with slight modifications. $100 \mu \mathrm{L}$ sample extract was reacted with $0.1 \mathrm{~mL}$ of $10 \%$ aluminium chloride solution (in ethanol), $0.1 \mathrm{~mL}$ of $1 \mathrm{M}$ potassium acetate, and $2.8 \mathrm{~mL}$ distilled water. The reaction mixture was incubated at room temperature for $30 \mathrm{~min}$. Absorbance was measured against the blank at $415 \mathrm{~nm}$. Quercetin was used as the reference standard. A calibration curve of quercetin was plotted by using the absorbance values against various concentrations $(100-1000 \mu \mathrm{g} / \mathrm{mL})$ of quercetin. The assays were done in triplicates and the results obtained were averaged and expressed as milligram quercetin equivalent (mg QE)/g dry weight of the biomass.

2.10. Free Radical Scavenging Assay. Antioxidant activity of the extracts were determined using DPPH (1, 1-diphenyl-2picrylhydrazyl) free radical scavenging assay with modifications [19]. 0.004\% DPPH solution in methanol was freshly prepared prior to analysis. $1 \mathrm{~mL}$ sample extract was added to $3 \mathrm{~mL}$ DPPH solution, vortexed, and incubated in the dark for $30 \mathrm{~min}$ at room temperature. The absorbance was measured at $517 \mathrm{~nm}$ against a DPPH blank. BHT (butylated hydroxytoluene) was used as the reference standard. DPPH scavenging activity was calculated using the following equation:

DPPH radical scavenging activity (\%)

$$
=\frac{\left[\left(\mathrm{Abs}_{\text {blank }}-\mathrm{Abs}_{\text {sample }}\right)\right]}{\left(\mathrm{Abs}_{\text {blank }}\right)} \times 100 \text {, }
$$

where $\mathrm{Abs}_{\text {blank }}$ is the absorbance of DPPH solution in methanol; $\mathrm{Abs}_{\text {sample }}$ is the absorbance of DPPH radical + sample extract/standard.

2.11. Ferric Reducing Antioxidant Power (FRAP) Assay. FRAP assay was done for determining the total antioxidant activity of the sample extracts with modifications [20]. Solutions of $300 \mathrm{mmol} / \mathrm{L}$, pH 3.6 sodium acetate buffer, $10 \mathrm{mmol} \mathrm{TPTZ} \mathrm{(2,}$ 4, 6-tri (2-pyridyl)-s-triazine) in $40 \mathrm{mmol}$ hydrochloric acid, and $20 \mathrm{mmol} / \mathrm{L} \mathrm{FeCl}_{3} \cdot 6 \mathrm{H}_{2} \mathrm{O}$ were prepared. A fresh working solution was prepared by mixing the three solutions in ratio of $10: 1: 1$, respectively. The temperature of the solution was raised to $37^{\circ} \mathrm{C}$ before use. Each sample extract of $100 \mu \mathrm{L}$ was allowed to react with $3 \mathrm{~mL}$ of FRAP solution for $30 \mathrm{~min}$ in the dark at room temperature. Absorbance of the reaction mixture was measured at $593 \mathrm{~nm}$ against a reagent blank. A standard curve was prepared using $\mathrm{FeSO}_{4}(100-2000 \mu \mathrm{g} / \mathrm{mL})$ solution and the results were expressed as $\mu \mathrm{mol} \mathrm{Fe}$ (II)/g dry weight of the plant material. BHT was used as the reference standard.

2.12. Preparation of Polymer Composites. $25 \mathrm{~g}$ of PVC was taken in a brabender plasticorder along with 40 phr of WBPB fibre and $5 \mathrm{phr}$ of PE-g-MA. Initially the blending of the mixture was done at $70^{\circ} \mathrm{C}$ with screw speed $40 \mathrm{rpm}$ for $3 \mathrm{~min}$. Following this, 15 phr lead carbonate and 5 phr dibutylpthalate were added to the mixture and the final blending was done at $150^{\circ} \mathrm{C}$ for $5 \mathrm{~min}$. The mixture was then transferred to a tray and the composite sheets were prepared by compression molding press (Santec, New Delhi) at $190^{\circ} \mathrm{C}$ under $80 \mathrm{MPa}$.

2.13. Thermogravimetric Analysis. Thermal properties of WBPB along with the polymer composite were measured in a thermogravimetric analyser (TGA) (TGA-50, Shimadzu) at a heating rate of $10^{\circ} \mathrm{C} / \mathrm{min}$ up to $600^{\circ} \mathrm{C}$ in nitrogen atmosphere.

2.14. Water Uptake Test. Percentage water uptake was measured by submerging the samples in distilled water at room temperature $\left(30^{\circ} \mathrm{C}\right)$ for different time periods after conditioning at $65 \%$ relative humidity and $30^{\circ} \mathrm{C}$ and expressed according to the formulae

$$
\text { Water uptake }(\%)=\frac{W_{s}-W_{1}}{W_{1}} \times 100 \text {; }
$$

see [21], where $W_{s}$ is the weight of sample after immersion in distilled water for a specified time period and $W_{1}$ is the weight of oven dried sample. 


\section{Results and Discussion}

3.1. Bioenergy Characterization (Elemental and Biochemical Analysis). Table 1 presents the characteristic composition of WBPB. Moisture content of the biomass was $8.6 \%$. Generally biomass samples with high moisture content are more suited for biochemical conversion than those with low moisture content for thermochemical conversion [22]. As such, WBPB with a moisture content of $8.6 \%$ seems to be a more suitable candidate for biochemical conversion. WBPB has an appreciable content of holocellulose $(58.67 \%)$ which further supports its candidature for biochemical conversion via fermentation; however a low lipid content of $0.89 \%$ renders it as a poor feedstock for biodiesel production. The ash content, volatile matter, and fixed carbon content in WBPB were 6.8, 75.3 , and $11.23 \%$, respectively. WBPB had high percentage of volatile matter and low ash content which is important with respect to their application in conversion processes, namely, gasification and pyrolysis; however greater research capacities are required for a better comprehensive understanding of biomass conversion processes for WBPB.

The biochemical constituents', namely, cellulose, hemicellulose, and lignin, content in WBPB was 37, 21.67, and $8.57 \%$, respectively. Bioethanol production from lignocellulosic feedstock has a direct relation with the amount of cellulose and hemicelluloses [23]. Cellulose and hemicellulose are the polysaccharides that are targeted for bioethanol production by hydrolyzing them to release sugars and subsequent fermentation of the sugars to ethanol [24]. In this regard, the higher quantum of holocellulose in WBPB $(58.67 \%)$ is indicative of prospective biochemical conversion via fermentation for bioethanol production.

Elemental analysis of WBPB indicates that it is a carbon and oxygen rich feedstock. The elemental content of carbon, hydrogen, nitrogen, and oxygen in WBPB was 43.07, 6.06, 1.23 , and $49.64 \%$, respectively. The empirical formula of WBPB is $\mathrm{C}_{44.86} \mathrm{H}_{75.75} \mathrm{NO}_{38.78}$. The $\mathrm{H} / \mathrm{C}$ and $\mathrm{O} / \mathrm{C}$ molar ratios (on an ash free dry basis) were calculated from elemental composition as 1.69 and 0.86 , respectively. The Gross calorific value (GCV) and Net calorific value (NCV) for WBPB were 15.22 and $12.49 \mathrm{MJ} / \mathrm{Kg}$, respectively. The higher proportion of hydrogen and oxygen compared with carbon reduces the energy value of biomass due to lower energy contained in carbon-oxygen and carbon-hydrogen bonds than in carboncarbon bonds [22].

3.2. FTIR Analysis. The FTIR spectrum of WBPB is presented in Figure 1. A large band $\left(3600-3100 \mathrm{~cm}^{-1}\right)$ is characteristic of polymeric involvement of hydroxyl groups and bonded $\mathrm{O}-\mathrm{H}$ stretching vibration present in carbohydrates (holocellulose) and lignin [25]. $\mathrm{CH}_{2}$ stretching vibrations $\left(3100-2800 \mathrm{~cm}^{-1}\right.$ ) imply the presence of lipid, whereas the absorption at $2920 \mathrm{~cm}^{-1}$ is specific for $\mathrm{CH}_{2}$ asymmetric stretching in lipid [26]. The C-H stretching bands $\left(1500-1300 \mathrm{~cm}^{-1}\right)$ and a C-O stretching band at $1030 \mathrm{~cm}^{-1}$ are attributed to the presence of cellulosic structure [26]. The absorption at $1640 \mathrm{~cm}^{-1}$ implies the presence of $\mathrm{C}=\mathrm{O}$ of carboxylic acid and their derivatives. The absorption $\left(1700-1500 \mathrm{~cm}^{-1}\right)$ corresponds to
TABLE 1: Properties of WBPB.

\begin{tabular}{lcc}
\hline Properties & & WBPB \\
\hline GCV MJ/Kg & & 15.22 \\
NCV MJ/Kg & $\mathrm{C}$ & 12.49 \\
\hline & $\mathrm{H}$ & 43.07 \\
Elemental analysis & $\mathrm{O}$ & 6.06 \\
(wt. \%) & (by difference) & 1.23 \\
& & 49.64 \\
\hline Empirical formula & & $\mathrm{C}_{44.86} \mathrm{H}_{75.75} \mathrm{NO}_{38.78}$ \\
H/C ratio & Moisture & 1.69 \\
O/C ratio & Aolatile matter & 0.86 \\
\hline & Ash & 8.6 \\
Proximate analysis & Fixed carbon (by & 6.8 \\
(wt. \%) & difference) & 11.23 \\
& Cellulose & 37 \\
& Hemicellulose & 21.67 \\
Lignocellulosic & Lignin & 8.57 \\
composition & & \\
(wt. \%) & &
\end{tabular}

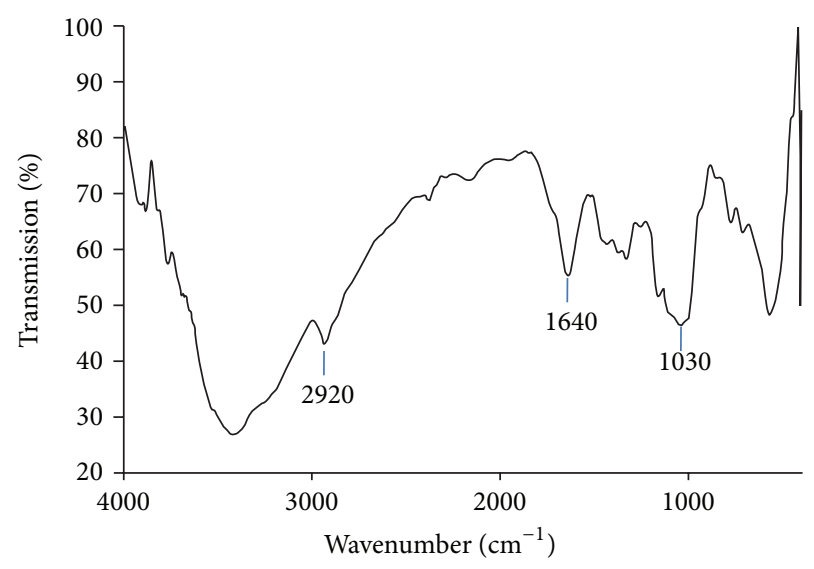

FIgURE 1: FTIR spectrum of WBPB.

the aromatic skeletal vibrations due to the presence of lignin [27]. The absorptions $\left(1200-900 \mathrm{~cm}^{-1}\right.$ ) are predominantly dominated by a sequence of bands owing to $\mathrm{C}-\mathrm{O}, \mathrm{C}-\mathrm{C}$, $\mathrm{C}-\mathrm{O}-\mathrm{C}$, and $\mathrm{C}-\mathrm{O}-\mathrm{P}$ stretching vibrations of polysaccharides $[28,29]$ as well as $\mathrm{CH}_{3}, \mathrm{CH}_{2}$ rocking modes [30].

3.3. Antioxidant Property Analysis. The study also takes into account the free radical scavenging potential (antioxidants) of WBPB as a part of additional waste valorization. The antioxidant properties of the extracts were assayed by \% DPPH scavenging and FRAP assay. Both assays for antioxidant activity used in this study were spectrophotometric methods. Majority of the antioxidant activity shown by plant extracts is due to the presence of flavones, isoflavones, flavonoids, anthocyanin, coumarin lignans, catechins, and isocatechins [31]. 


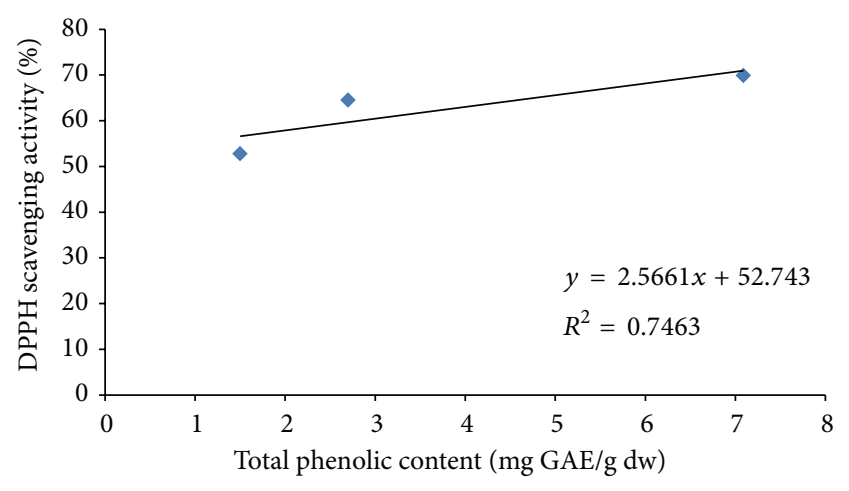

Figure 2: Correlation between phenolic content and \% DPPH scavenging activity of WBPB extracts.

Table 2 shows the antioxidant activity, total phenolic, and total flavonoid content of WBPB (dry weight basis). Among all the tested extracts (aqueous, ethanol, and methanol), methanolic extract showed the highest \% DPPH as well as FRAP activity. The higher antioxidant activity of the methanolic extract can be attributed to the presence of high phenolic and flavonoid compounds in the extract.

Moreover, a positive correlation between the phenolic content and \% DPPH scavenging activity $\left(R^{2}=0.7463\right.$, Figure 2), flavonoid content and \% DPPH scavenging activity $\left(R^{2}=0.8118\right.$, Figure 3$)$, total phenolic content and FRAP activity $\left(R^{2}=0.9928\right.$, Figure 4$)$, and flavonoid content and FRAP activity $\left(R^{2}=0.9733\right.$, Figure 5$)$ further support the experimental findings. The positive linear correlation results are indicative of the importance of phenolic compounds in the antioxidant behavior of WBPB extracts and also that they contribute significantly to the total antioxidant capacity as determined by the FRAP assay. The resultant differences in the values for the tested assays (DPPH and FRAP) can be attributed to the difference in reaction mechanisms and different reaction conditions. The reducing power property as evident from the FRAP assay indicates that the antioxidant compounds are electron donors and can reduce the oxidized intermediates to a more stable form [32]. Total phenolics and flavonoid content in various solvent extracts of pseudostem of different banana cultivars was reported to be in the range of 7.58 to $291 \mathrm{mg}$ gallic acid equivalent (GAE/g of extract) and 4 to $80 \mathrm{mg}$ catechin equivalent (CE/g of extract) [33]. They reported that acetone extract showed the highest antioxidant activity, whereas the methanolic extract exhibited the highest metal chelating potential in all the tested in vitro model systems. Ethanolic extract of Musa acuminata rhizome is reported to show significant antiproliferative and antioxidant activities [34].

The findings pertaining to free radical scavenging potential of WBPB can serve as an incremental step in identification of active antioxidant components present in the extracts and appraisal of their subsequent usage in commercial applications.

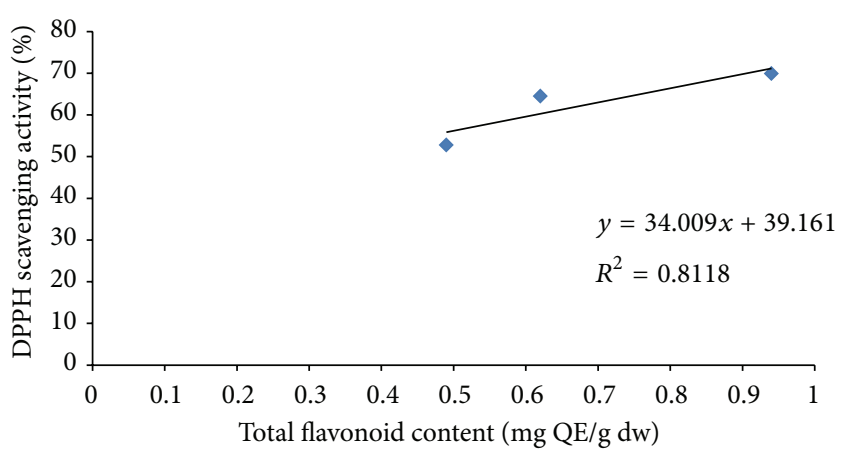

FIGURE 3: Correlation between flavonoid content and \% DPPH scavenging activity of WBPB extracts.

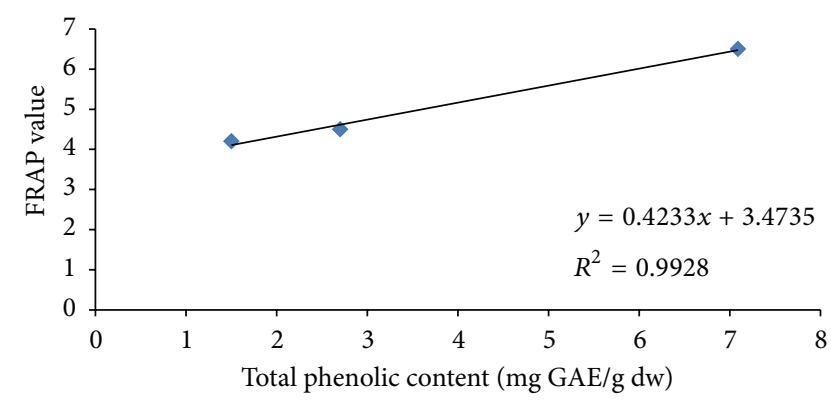

FIGURE 4: Correlation between phenolic content of WBPB extracts and FRAP assay.

3.4. WPBP as Reinforcing Agent in Polymer Composites. The study also investigated WBPB fibre as natural filler in PVC polymer composite. PVC is one of the most important polymers being used for a wide variety of applications. PVC is used in clothing, household sewerage pipes, window and door frames, and electrical purposes. PVC has less thermal stability at higher temperatures [35]. The thermal stability along with other properties can be improved by making composites with fillers like clay [36], metal oxides [37], and different types of cellulosic powders [38]. In modern times, fillers derived from natural origin are gaining wider popularity due to their low cost, easy availability, low density, high specific strength, and renewability [39].

The use of banana fibre and silica powder as reinforcing agent in epoxy resin matrix has been reported in previous literatures [40, 41]. Joseph et al. have studied the mechanical properties of phenol formaldehyde composite reinforced with banana and glass fibre [42]. Dynamic mechanical analysis of banana fibre reinforced polyester composite has been studied [43]. Incorporation of banana pseudostem has been reported to improve the thermal stability of polyvinyl chloride [44]. However, it is noteworthy to mention that most of previous investigations have addressed the use of banana fibre in different matrix without specifically mentioning the type of banana species used. But we in our investigation are attempting to specifically highlight Musa balbisiana Colla pseudostem fibre as a reinforcing agent in PVC polymer composites. 
TABLE 2: Antioxidant activity and total phenolic and total flavonoid content of WBPB extracts (dry weight basis).

\begin{tabular}{lcccc}
\hline Extract & $\begin{array}{c}\text { Antioxidant activity* } \\
\text { \% DPPH scavenging } \\
\text { activity }\end{array}$ & $\begin{array}{c}\text { FRAP } \\
(\mu \mathrm{mol} \mathrm{Fe}(\mathrm{II}) / \mathrm{g} \mathrm{dw})\end{array}$ & $\begin{array}{c}\text { Total phenolic content } \\
(\mathrm{mg} \mathrm{GAE} / \mathrm{g} \mathrm{dw})^{*}\end{array}$ & $\begin{array}{c}\text { Total flavonoid content } \\
(\mathrm{mg} \mathrm{QE} / \mathrm{g} \mathrm{dw})^{*}\end{array}$ \\
\hline $\mathrm{AE}$ & 52.8 & 4.2 & 1.50 & 0.49 \\
$\mathrm{EE}$ & 64.5 & 4.5 & 2.70 & 0.62 \\
$\mathrm{ME}$ & 69.9 & 6.5 & 7.09 & 0.94 \\
$\mathrm{BHT}$ & 87 & 34.6 & - & - \\
\hline
\end{tabular}

AE: aqueous extract, EE: ethanolic extract, and ME: methanolic extract.

BHT: butylated hydroxytoluene, GAE: gallic acid equivalent, and QE: quercetin equivalent.

${ }^{*}$ Mean values are reported.

TABLE 3: Temperature profile of PVC, WBPB, and WBPB polymer composite.

\begin{tabular}{|c|c|c|c|c|c|c|c|c|}
\hline \multirow[t]{2}{*}{ Sample } & \multirow[t]{2}{*}{$T_{i}$} & \multirow[t]{2}{*}{${ }^{\mathrm{a}} T_{m}$} & \multirow[t]{2}{*}{${ }^{\mathrm{b}} T_{m}$} & \multicolumn{4}{|c|}{$\begin{array}{c}\text { Temperature of decomposition }\left(T_{d}\right) \text { in }{ }^{\circ} \mathrm{C} \\
\text { at different weight loss }(\%)\end{array}$} & \multirow{2}{*}{$\begin{array}{l}\mathrm{Rw} \% \text { at } \\
600^{\circ} \mathrm{C}\end{array}$} \\
\hline & & & & $20 \%$ & $40 \%$ & $60 \%$ & $80 \%$ & \\
\hline PVC & 274 & 296 & 461 & 287 & 308 & 345 & 505 & 12 \\
\hline WBPB & 314 & - & 350 & 329 & 352 & 364 & 512 & 15 \\
\hline $\begin{array}{l}\text { WBPB polymer } \\
\text { composite }\end{array}$ & 280 & 300 & 463 & 291 & 313 & 465 & - & 29 \\
\hline
\end{tabular}

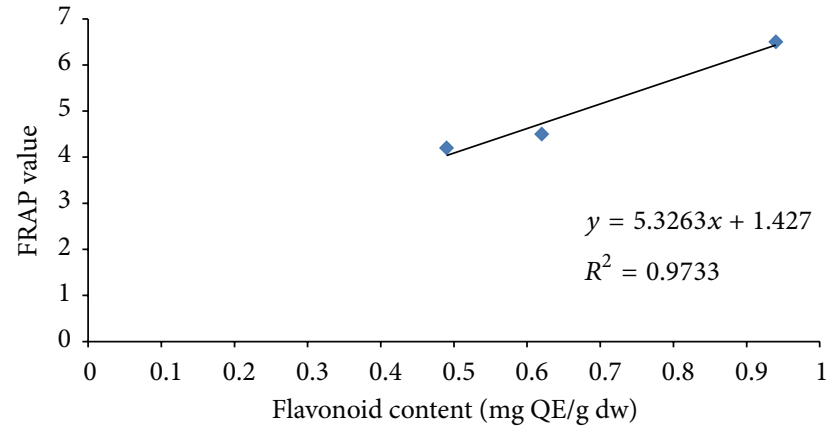

FIGURE 5: Correlation between flavonoid content of WBPB extracts and FRAP assay.

3.4.1. Thermal Properties of WBPB Polymer Composite. Table 3 shows the initial decomposition temperature $\left(T_{i}\right)$, maximum pyrolysis temperature $\left(T_{m}\right)$ decomposition temperature at different weight loss $(\%)\left(T_{d}\right)$, and residual weight (Rw \%) for PVC, WBPB, and WBPB reinforced PVC composites. $T_{i}$ values for the composite were in between that of PVC and WBPB. Both PVC and the composite showed two stages of decomposition. $T_{m}$ values for PVC, WBPB, and the composite may be attributed to depolymerisation of cellulose, glycosidic linkage of cellulose, thermal decomposition of cellulose [45], and/or dehydrochlorination of PVC [46]. The thermal degradation profile of PVC, WBPB, and the composite is presented in Figure 6. In the composite $T_{m}$ values for both stages of pyrolysis shifted marginally towards higher temperature. $T_{d}$ values of the composite were in between the range for PVC and fibres up to $40 \%$ decomposition, beyond which it increased. Rw value of composite was higher than that of PVC and WBPB.

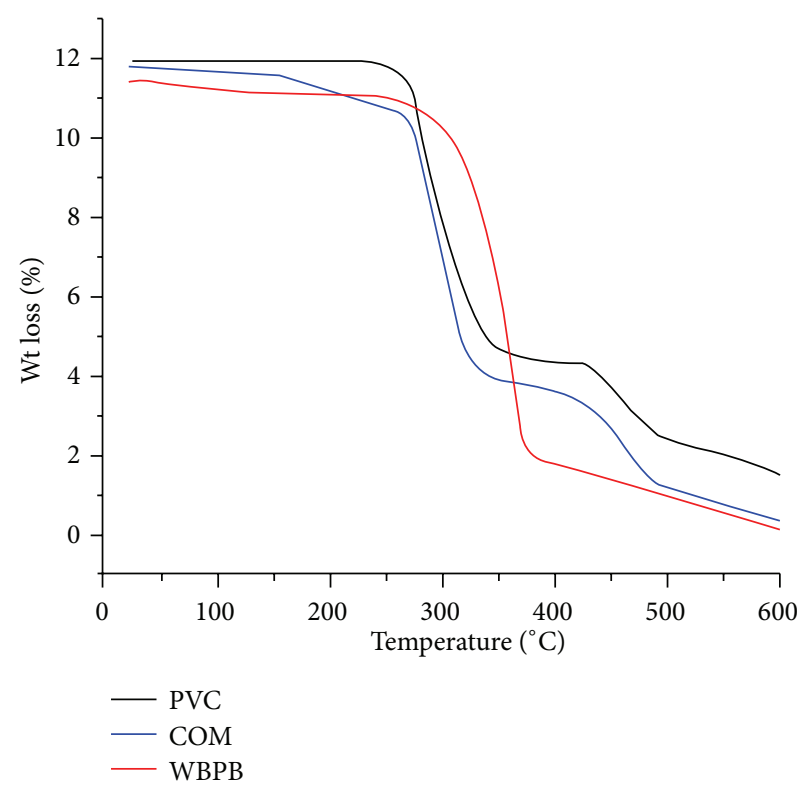

FIgURE 6: Thermal degradation profile of PVC, WBPB, and composite.

3.4.2. Water Uptake Test of WBPB Polymer Composite. Water uptake test for WBPB-PVC based composite was done. Water absorption values of the composite were $1.35 \%$ and $11.47 \%$ after 2 hour and 72 hour of immersion in distilled water. Water absorption of WBPB fibre was very high due to its hydrophilic nature. The decrease in water absorption by the WBPB polymer composite was due to the presence of compatibiliser PE-g-MA which enhanced the adhesion between PVC and fibre. 


\section{Conclusion}

The biomass intensive future energy scenario looks promising owing to the availability of numerous potent bio-based feedstock. Agrowastes with higher quantum of organic constituents can potentially be a viable source with regard to energy recovery, environmental upgradation, and waste valorization. The characterization of WBPB in the realm of agrowaste management suggests that it is a prospective biobased feedstock and can be used for bioethanol production thereby amending to the demands of second generation biofuels. Moreover, efficient free radical scavenging potential (utilizable as antioxidants) further adds to the economics of feedstock utility thereby supporting its prospective candidature for biorefineries. Improved thermal stability and moisture resistance of the WBPB polymer composite suggests that waste Musa balbisiana Colla fibre could be used as a reinforcing agent in PVC composites, finding applications in structural components like window, window profiles, table tops, partition walls, and so forth. WBPB represents a largely unexploited lignocellulosic bio-based resource whose true potential has not been fully realized and henceforth requires promising research in similar lines. The study concludes that WBPB can be a prospective bioenergy feedstock for futuristic energy utilization, has effective free radical scavenging potential, and can also be used as a reinforcing agent in PVC polymer composites. WBPB represents a grossly neglected waste biomass with untapped potential and quite arguably warrants further research endeavors for a better comprehensive understanding of additional waste valorization.

\section{Conflict of Interests}

The authors declare that there is no conflict of interests regarding the publication of this paper.

\section{Acknowledgments}

The first author (Krishna Gogoi) sincerely acknowledges CSIR, India, for financial support in the form of senior research fellowship (SRF). The second author (Mayur Mausoom Phukan) expresses his sincere sense of gratitude to the Department of Science \& Technology, Government of India, for providing research grant in the form of DST-INSPIRE fellowship.

\section{References}

[1] A. Demirbaş, "Biomass resource facilities and biomass conversion processing for fuels and chemicals," Energy Conversion and Management, vol. 42, no. 11, pp. 1357-1378, 2001.

[2] M. A. Sanderson, F. Agblevor, M. Collins, and D. K. Johnson, "Compositional analysis of biomass feedstocks by near infrared reflectance spectroscopy," Biomass and Bioenergy, vol. 11, no. 5, pp. 365-370, 1996.

[3] R. C. Sun, "Cereal straw as a resource for sustainable biomaterials and biofuels-chemistry, extractives, lignins, hemicelluloses and cellulose," Industrial Crops and Products, vol. 40, pp. 33-34, 2012.
[4] Y. Moriguchi, "Recycling and waste management from the viewpoint of material flow accounting," Journal of Material Cycles and Waste Management, vol. 1, pp. 2-9, 1999.

[5] C. I. Koncsag, D. Eastwood, A. E. C. Collis et al., "Extracting valuable compounds from straw degraded by Pleurotus ostreatus," Resources, Conservation and Recycling, vol. 59, pp. 14-22, 2012.

[6] M. P. Adinugraha, D. W. Marseno, and Haryadi, "Synthesis and characterization of sodium carboxymethylcellulose from cavendish banana pseudo stem (Musa cavendishii LAMBERT)," Carbohydrate Polymers, vol. 62, no. 2, pp. 164-169, 2005.

[7] P. Meenakshi, S. E. Noorjahan, R. Rajini, U. Venkateswarlu, C. Rose, and T. P. Sastry, "Mechanical and microstructure studies on the modification of CA film by blending with PS," Bulletin of Materials Science, vol. 25, no. 1, pp. 25-29, 2002.

[8] K. Li, S. Fu, H. Zhan, Y. Zhan, and L. A. Lucia, "Analysis of the chemical composition and morphological structure of banana pseudostem," BioResources, vol. 5, no. 2, pp. 576-585, 2010.

[9] E. A. Davidson, T. D. D. A. Sá, C. J. R. Carvalho et al., "An integrated greenhouse gas assessment of an alternative to slashand-burn agriculture in eastern Amazonia," Global Change Biology, vol. 14, no. 5, pp. 998-1007, 2008.

[10] FAOSTAT: ProdSTAT: Crops, Food and Agriculture Organization, 2005.

[11] D. Mohapatra, S. Mishra, and N. Sutar, "Banana and its byproduct utilisation: an overview," Journal of Scientific and Industrial Research, vol. 69, no. 5, pp. 323-329, 2010.

[12] L. D’Souza, P. Devi, M. P. Divya Shridhar, and C. G. Naik, "Use of Fourier Transform Infrared (FTIR) spectroscopy to study cadmium-induced changes in Padina tetrastromatica (Hauck)," Analytical Chemistry Insights, vol. 3, pp. 135-143, 2008.

[13] A. Demirbaş, "Calculation of higher heating values of biomass fuels," Fuel, vol. 76, no. 5, pp. 431-434, 1997.

[14] A. Evald, J. Koppejan, W. Livingston, T. Nussbaumer, I. Obernberger, and Q. Skreiberg, "Biomass fuel properties and basic principles of biomass combustion," in Handbook of Biomass Combustion and Co-Firing, pp. 7-53, Earthscan, London, UK, 2008.

[15] Annual Book of ASTM Standards, Part 26, American Society of Testing Materials, Easton, D 3173-73, D 3175-77, D-3174-73, 1977.

[16] P. J. van Soest, Nutritional Ecology of the Ruminant, Ruminant Metabolism, Nutritional Strategy, the Cellulolytic Fermentation and the Chemistry of Forages and Plant Fibres, Cornell University Press, London, UK, 1987.

[17] V. L. Singleton and J. A. Rossi, "Colorimetry of total phenolics with phosphomolybdic-phosphotungstic acid reagents," American Journal of Enology and Viticulture, vol. 16, no. 3, pp. 144-158, 1965.

[18] C. Chang, M. Yang, H. Wen, and J. Chern, "Estimation of total flavonoid content in propolis by two complementary colometric methods," Journal of Food and Drug Analysis, vol. 10, no. 3, pp. 178-182, 2002.

[19] A. Serpen, E. Capuano, V. Fogliano, and V. Gökmen, "A new procedure to measure the antioxidant activity of insoluble food components," Journal of Agricultural and Food Chemistry, vol. 55 , no. 19, pp. 7676-7681, 2007.

[20] I. F. F. Benzie and J. J. Strain, "The ferric reducing ability of plasma (FRAP) as a measure of "antioxidant power": the FRAP assay," Analytical Biochemistry, vol. 239, no. 1, pp. 70-76, 1996.

[21] B. K. Deka, N. Dutta, and T. K. Maji, "Effect of different compatibilisers and nanoclays on the physical properties of 
wood (Phragmites karka)-polymer composites," Polymers from Renewable Resources, vol. 2, no. 3, pp. 87-104, 2011.

[22] P. McKendry, "Energy production from biomass (part 1): overview of biomass," Bioresource Technology, vol. 83, no. 1, pp. 37-46, 2002.

[23] C. Karunanithy, K. Muthukumarappan, and J. L. Julson, "Enzymatic hydrolysis of corn stover pretreated in high shear bioreactor," in Proceedings of the American Society of Agricultural and Biological Engineers Annual International Meeting, pp. 36033611, Providence, RI, USA, July 2008.

[24] M. Balat, "Production of bioethanol from lignocellulosic materials via the biochemical pathway: a review," Energy Conversion and Management, vol. 52, no. 2, pp. 858-875, 2011.

[25] K. Bilba, M. A. Arsene, and A. Ouensanga, "Study of banana and coconut fibers: botanical composition, thermal degradation and textural observations," Bioresource Technology, vol. 98, no. 1, pp. 58-68, 2007.

[26] B. Stuart, Infrared Spectroscopy: Fundamentals and Applications, John Wiley \& Sons, West Sussex, UK, 1st edition, 2002.

[27] A. J. Romero-Anaya, A. Molina, P. Garcia, A. A. Ruiz-Colorado, A. Linares-Solano, and C. Salinas-Martínez de Lecea, "Phosphoric acid activation of recalcitrant biomass originated in ethanol production from banana plants," Biomass and Bioenergy, vol. 35, no. 3, pp. 1196-1204, 2011.

[28] W. F. Wolkers, A. E. Oliver, F. Tablin, and J. H. Crowe, "A Fourier-transform infrared spectroscopy study of sugar glasses," Carbohydrate Research, vol. 339, no. 6, pp. 1077-1085, 2004.

[29] N. Yee, L. G. Benning, V. R. Phoenix, and F. G. Ferris, "Characterization of metal-cyanobacteria sorption reactions: a combined macroscopic and infrared spectroscopic investigation," Environmental Science and Technology, vol. 38, no. 3, pp. 775-782, 2004.

[30] M. Wolpert and P. Hellwig, "Infrared spectra and molar absorption coefficients of the 20 alpha amino acids in aqueous solutions in the spectral range from 1800 to $500 \mathrm{~cm}^{-1}$," Spectrochimica Acta, vol. 64, no. 4, pp. 987-1001, 2006.

[31] F. Aqil, I. Ahmad, and Z. Mehmood, "Antioxidant and free radical scavenging properties of twelve traditionally used Indian medicinal plants," Turkish Journal of Biology, vol. 30, no. 3, pp. 177-183, 2006.

[32] G. Yen and H. Chen, "Antioxidant activity of various tea extracts in relation to their antimutagenicity," Journal of Agricultural and Food Chemistry, vol. 43, no. 1, pp. 27-32, 1995.

[33] K. Saravanan and S. M. Aradhya, "Polyphenols of pseudostem of different banana cultivars and their antioxidant activities," Journal of Agricultural and Food Chemistry, vol. 59, no. 8, pp. 3613-3623, 2011.

[34] K. P. S. Adinarayana and A. P. Babu, "Anti-oxidant activity and cytotoxicity of ethanolic extracts from rhizome of Musa acuminata," Natural Science, vol. 3, no. 4, pp. 291-294, 2011.

[35] A. A. Yassin and M. W. Sabaa, "Degradation and stabilization of poly(vinyl chloride)," Journal of Macromolecular Science C: Polymer Reviews, vol. 30, no. 3-4, pp. 491-558, 1990.

[36] T. Peprnicek, A. Kalendova, E. Pavlova, J. Simonik, J. Duchet, and J. F. Gerard, "Poly(vinyl chloride)-paste/clay nanocomposites: investigation of thermal and morphological characteristics," Polymer Degradation and Stability, vol. 91, no. 12, pp. 33223329, 2006.

[37] I. A. Ibrahim, F. A. Mohamed, and E. J. Lavernia, "Particulate reinforced metal matrix composites-a review," Journal of Materials Science, vol. 26, no. 5, pp. 1137-1156, 1991.
[38] H. Kiani, A. Ashori, and S. A. Mozaffari, "Water resistance and thermal stability of hybrid lignocellulosic filler-PVC composites," Polymer Bulletin, vol. 66, no. 6, pp. 797-802, 2011.

[39] M. J. John and S. Thomas, "Biofibres and biocomposites," Carbohydrate Polymers, vol. 71, no. 3, pp. 343-364, 2008.

[40] V. K. Singh, P. C. Gope, C. Sakshi, and B. D. Singh, "Mechanical behavior of banana fiber based hybrid bio composites," Journal of Materials and Environmental Science, vol. 3, no. 1, pp. 185-194, 2012.

[41] M. A. Maleque, F. Y. Belal, and S. M. Sapuan, "Mechanical properties study of pseudo-stem banana fiber reinforced epoxy composite," Arabian Journal for Science and Engineering B, vol. 32, no. 2, pp. 359-364, 2007.

[42] S. Joseph, M. S. Sreekala, Z. Oommen, P. Koshy, and S. Thomas, "A comparison of the mechanical properties of phenol formaldehyde composites reinforced with banana fibres and glass fibres," Composites Science and Technology, vol. 62, no. 14, pp. 1857-1868, 2002.

[43] L. A. Pothan, Z. Oommen, and S. Thomas, "Dynamic mechanical analysis of banana fiber reinforced polyester composites," Composites Science and Technology, vol. 63, no. 2, pp. 283-293, 2003.

[44] E. S. Zainudin, S. M. Sapuan, K. Abdan, and M. T. M. Mohamad, "Thermal degradation of banana pseudo-stem filled unplasticized polyvinyl chloride (UPVC) composites," Materials and Design, vol. 30, no. 3, pp. 557-562, 2009.

[45] K. N. Indira, P. Jyotishkumar, and S. Thomas, "Thermal stability and degradation of banana fibre/PF composites fabricated by RTM," Fibers and Polymers, vol. 13, no. 10, pp. 1319-1325, 2012.

[46] Y. Z. Meng and S. C. Tjong, "Preparation and properties of injection-moulded blends of poly(vinyl chloride) and liquid crystal copolyester," Polymer, vol. 40, no. 10, pp. 2711-2718, 1999. 

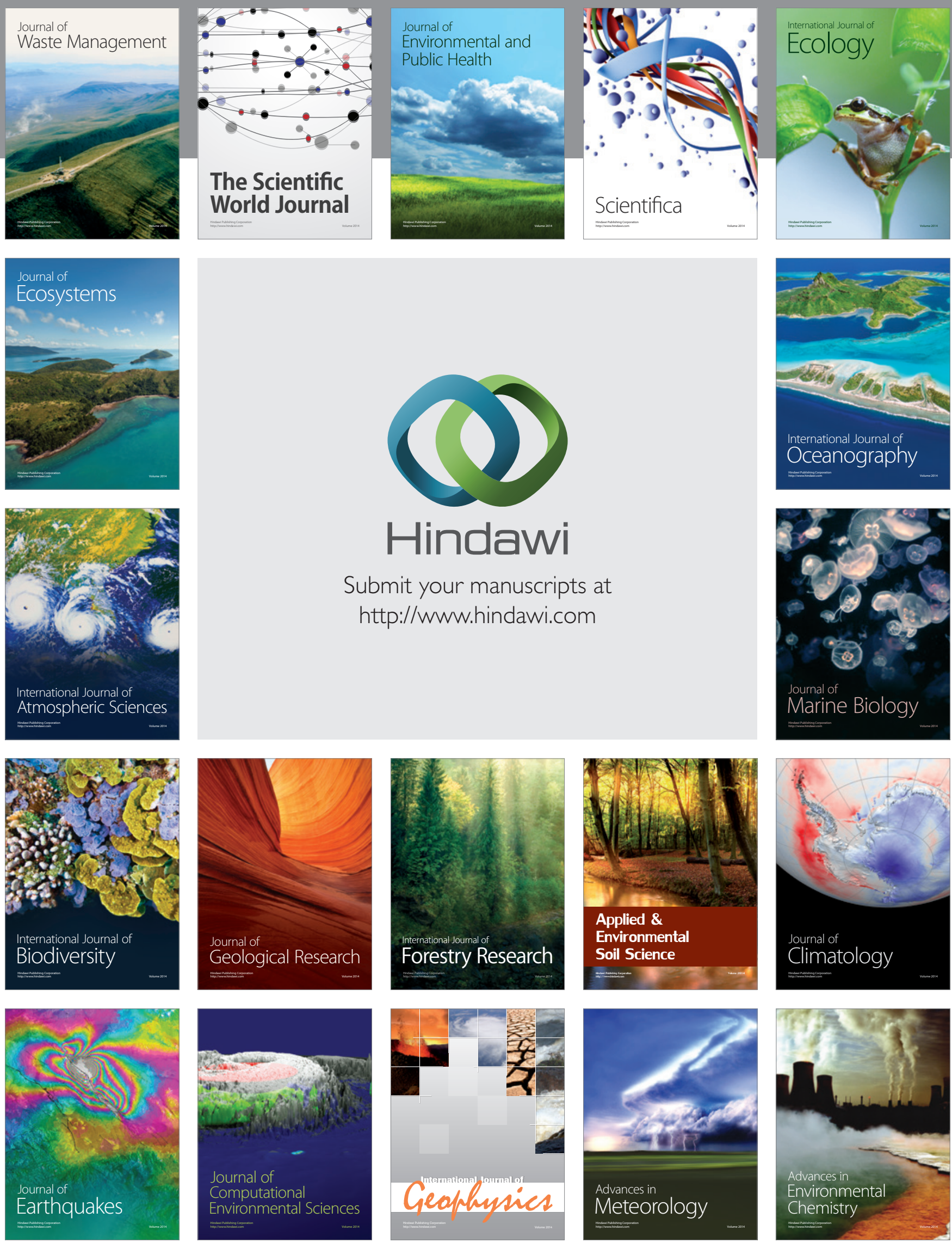